\title{
Protective Effect of Se-Methylselenocysteine on Elaidic Acid-Induced Inflammation in Human Arterial Endothelial Cells
}

\author{
Jizhu XIA ${ }^{1}$, Xiaorong XIA ${ }^{1}$, Wenyuan WANG $^{1}$, Jiyi XIA ${ }^{2}$ and Mingxing LI ${ }^{1}$ \\ ${ }^{1}$ Department of Ultrasound, The Affiliated Hospital of Southwest Medical University, \\ Luzhou, Sichuan, 646000, China \\ ${ }^{2}$ Southwest Medical University, Luzhou, Sichuan, 646000, China
}

(Received June 9, 2020)

\begin{abstract}
Summary This study was designed to investigate the anti-inflammatory effect of Se-methylselenocysteine (MSC) on elaidic acid (9t18:1, EA) induced human arterial endothelial cells (HAECs). MTT and flow cytometry were used to determine cell viability and cell apoptosis respectively. Western blotting was used to assess protein expression of intercellular adhesion molecular 1 (ICAM-1), E-selectin, interleukin-8 (IL-8), endothelial nitric oxide synthase (e-NOS) and phospholipases A2 (PLA2), while enzyme-linked immunosorbent assay (ELISA) was performed to examine the secretion level of nitric oxide (NO). In the cell viability assay, EA significantly decreased cell viability when compared with negative control (NC) group, and MSC effectively reversed this adverse effect, especially at the concentration of $200 \mu \mathrm{mol} / \mathrm{L}$ with $24 \mathrm{~h}$ incubation. Also, the same concentration of MSC prevented HAECs cell apoptosis induced by EA. In addition, we found that the expression of ICAM-1, E-selectin, IL-8 and PLA2 were significantly increased and e-NOS decreased in EA group compared with NC group. Inhibition of PLA2 promoted ICAM-1, E-slectin and IL-8 expression in HAECs induced by EA. And MSC down-regulated the secretion of NO level in EA-induced HAECs. Based on these results, we concluded that MSC activated PLA2 which regulated the expression of ICAM-1, E-selectin and IL-8 to protect inflammation induced by EA in HEACs.
\end{abstract}

Key Words Se-methylselenocysteine, elaidic acid, endothelial cell, inflammation, PLA2

Trans fatty acids (TFAs) have attracted wide attention on cardiovascular health for a long time. Epidemiology evidence have demonstrated that industrial TFAs (I-TFAs) promotion the expression of inflammatory cytokines with the main component of elaidic acid (9t18:1, EA) (1). Also, published clinical studies have demonstrated that I-TFAs are closely related to endothelial cell damage, cadiovascular diseases (CVDs) and insulin resistance $(2,3)$.

The function of endothelial cells is mainly related to angiogenesis and formation of vascular wall and maintenance of vascular integrity and permeability. Harvey et al. (4) reported that EA induce endothelial cell dysfunction by elevating levels of inflammation cytokines such as intercellular adhesion molecular 1 (ICAM-1). Iwata et al. (5) found that EA promote endothelial cell injury by increasing nuclear factor- $\kappa \mathrm{B}(\mathrm{NF}-\kappa \mathrm{B})$ expression and influencing the production of insulin-mediated nitric oxide (NO) level. Furthermore, I-TFAs also increasing the risk of atherosclerosis by inhibiting the synthesis of polyunsaturated fatty acids (PUFA) in arterial cells, and EA can incorporate into phospholipids on endothelial cell membranes and then trigger the inflammation response (6).

Cell membrane plays a crucial role in cell biological

E-mail: xiajizhu2@yeah.net activities and energy metabolism. Phospholipids, the most important part of cell membrane, are involved in lots of cell activities, such as information transmission, external material substance and exchange. Studies demonstrated that phospholipids could be degraded into arachidonic acid (AA) and other lysophospholipids by stimulation of various factors. These degradation products will finally contribute for vascular injury (7).

Phospholipase is an important substance on cell membrane that regulates phospholipid synthesis and metabolism. Phospholipases A2 (PLA2) is one of the major isomers of phospholipases which are divided into three types, secretory phospholipases A2 (sPLA2), cytoplasmic phospholipases A2 (cPLA2) and calcium-independent phospholipases A2 (iPLA2). It has been reported that PLA2 could hydrolyze phospholipids, generate AA and other free fatty acids (7).

Selenium, one of the most essential non-metal trace elements in human, closely related to many diseases related to chronic inflammation, like inflammatory bowel diseases, rheumatoid arthritis, and atherosclerosis $(8$, 9). Previous studies have proved that selenium may block many key processes to protect vascular injury. The underlying mechanism of selenium on protect endothelial cell inflammation could be summarize as reduction of recruitment of inflammatory cells by inhibition activation of p38 MAPK (10), and inhibition of 
endothelial dysfunction and endothelial cell apoptosis by increasing antioxidase activity (11), reverse NO release (12), down-regulating caspase-3 and Bax expression (13). But few articles investigated the role of selenium on activity of phospholipases and the following anti-inflammation process.

Therefore, the present study was designed to explore the effect of Se-methylselenocysteine (MSC) on bio-activity of PLA2, and to evaluate following influence to human arterial endothelial cells (HAECs) inflammation induced by EA.

\section{MATERIALS AND METHODS}

Regents. HAEC cells were bought from Cell Bank of the Chinese Academy of Science (Shanghai, China). Elaidic acid, MTT, DMSO, Se-methylselenocysteine (MSC; purity $\geq 95 \%$ ) were obtained from Sigma (St. Louis, USA). Dulbecco's modided eagle medium (DMEM), fetal bovine serum (FBS), total RNA extraction kit (TRIzol), annexin V-FITC apoptosis detection kit and enhanced chemiluminescence (ECL) kit were bought from Invitrogen (Carlsbad, USA). Trans Script assay kit, real time PCR assay kit, polyclonal ICAM-1, E-selectin, IL-8, e-NOS, iPLA2, sPLA2, cPLA2 and p-cPLA2 antibodies were obtained from Santa Cruz Biotechnology (California, USA).

Cell culture and treatment. Cells were maintained in an incubator at $37^{\circ} \mathrm{C}$ with $5 \% \mathrm{CO}_{2}$, supplemented with DMEM medium containing 10\% fetal bovine serum, $100 \mu \mathrm{g} / \mathrm{mL}$ penicillin $\mathrm{G}$, and $100 \mu \mathrm{g} / \mathrm{mL}$ streptomycin sulfate, and medium was changed every $3 \mathrm{~d}$.

MTT assay. MTT assay was curried out to assess cell viability. Briefly, cells were divided into 5 groups: negative control (NC) group, elaidic acid (EA) group (50 $\mu \mathrm{mol} / \mathrm{L}$ ), EA+MSC group ( $50 \mu \mathrm{mol} / \mathrm{L}+100 \mu \mathrm{mol} / \mathrm{L}, 50$ $\mu \mathrm{mol} / \mathrm{L}+200 \mu \mathrm{mol} / \mathrm{L}, 50 \mu \mathrm{mol} / \mathrm{L}+400 \mu \mathrm{mol} / \mathrm{L})$. The concentrations of EA and MSC used in this study were according to previous study $(14,15)$. Three thousand cells per well were seeded into 96-well plates and incubated for $24 \mathrm{~h}$ and $48 \mathrm{~h}$ with different reagents. After incubating with MTT for $4 \mathrm{~h}$, dimethyl sulfoxide was added in the dark and co-culture with cells for another $10 \mathrm{~min}$. Finally, OD value was recorded at $570 \mathrm{~nm}$.

Flow cytometry. Cells were cultured and treated with different reagents as the same as MTT assay. Forty-eight hours later, flow cytometric assay was used to determine apoptosis through an Annexin V-FITC apoptosis detection kit following the manufacturer's protocol.

Western blot. Cells were divided into following groups: $\mathrm{NC}$ group, EA group; EA+MSC group $(50 \mu \mathrm{mol} / \mathrm{L}+$ $100 \mu \mathrm{mol} / \mathrm{L}, \quad 50 \mu \mathrm{mol} / \mathrm{L}+200 \mu \mathrm{mol} / \mathrm{L}, \quad 50 \mu \mathrm{mol} / \mathrm{L}+$ $400 \mu \mathrm{mol} / \mathrm{L}) ; \mathrm{EA}+\mathrm{MSC}+\mathrm{IB}$ group: cells were pretreated with different inhibitors for $1 \mathrm{~h}$, and then cultured with EA and MSC for $24 \mathrm{~h}$. IB refers to inhibitors for PLA2, including PYR (cPLA2 inhibitor), DTT (sPLA2 inhibitor) and BEL (iPLA2 inhibitor). The incubation time and concentration of inhibitors were followed by the previous report (16).

Proteins were extracted using RIPA buffer containing cocktail protease inhibitor. Total concentration of pro-

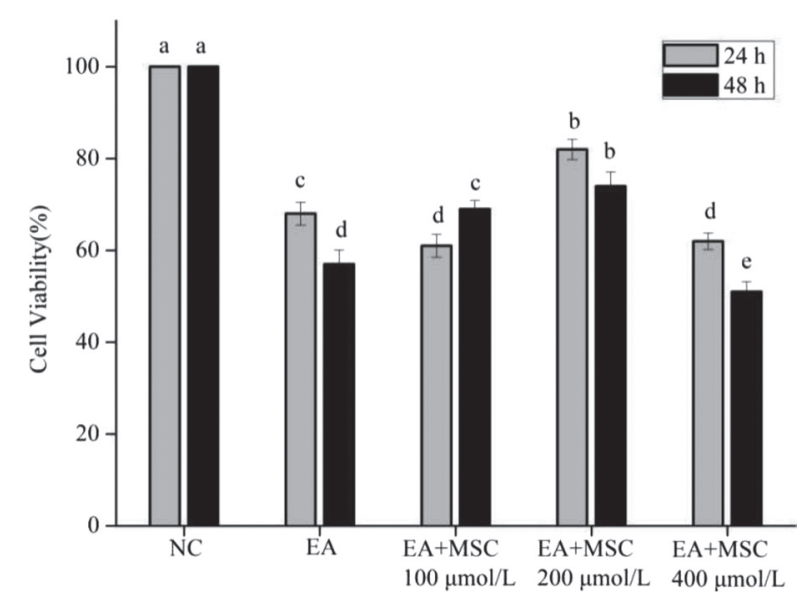

Fig. 1. Effect of EA and MSC on HAECs viability. Cells were treated with EA or EA+MSC for 24 or $48 \mathrm{~h}$. Data are expressed as mean \pm SD. Different characters in each set $(24 \mathrm{~h}, 48 \mathrm{~h})$ mean significant differences $(p<0.05)$.

tein was measured by BCA assay. Protein samples $(20 \mu \mathrm{g})$ were separated by sodium dodecyl sulfate-polyacylamide gel electrophoresis (SDS-PAGE) gel and blotted onto ployvinylidene difluoride (PVDF) membranes. After blocked with 5\% non-fat milk for $1 \mathrm{~h}$, membranes were subsequently incubated with primary antibodies and HRP-conjugated secondary antibody. Signals were measured by the enhanced chemiluminescence (ECL) kit.

Enzyme-linked immunosorbent assay (ELISA). Effect of EA and MSC on NO and prostaglansin E2 (PGE2) release level in HAECs were determined by ELISA assay. HAECs were seeded into 96-well plates at the density of $1 \times 10^{5}$ cells per mL. Cells were incubated with EA and MSC as the same as described in MTT assay, and the culture supernatants was prepared for ELISA assay according to the manufacturer's protocol using NO and PGE2 ELISA kits.

Statistical analysis. All assays were performed in triplicate except for the MTT $(n=6)$. All experimental data were presented as mean \pm standard deviation. Oneway ANOVA followed by Tukey's test was used to determine differences between groups with SPSS 22.0. p-values of less than 0.05 were considered statistically significant.

\section{RESULTS}

\section{Cell viability}

Cell viability of HAECs was detected by MTT assay after cells were treated with different agents for $24 \mathrm{~h}$ or $48 \mathrm{~h}$. As the results showed in Fig. 1, the cell viability decreased significantly after treated with $50 \mu \mathrm{mol} / \mathrm{L}$ EA compared with NC group $(p<0.05)$, and the cell viability were $68.21 \pm 2.55 \%$ and $57.85 \pm 3.11 \%$ at $24 \mathrm{~h}$ and $48 \mathrm{~h}$ respectively. Compared with the EA group (48 h), the cell viability was dramatically increased when treated with EA $+100 \mu \mathrm{mol} / \mathrm{L}$ MSC for $48 \mathrm{~h}(57.28 \pm$ $3.17 \%$ vs. $69.58 \pm 1.91 \%, p<0.05)$. Moreover, the result showed that comparison with other treated group: EA+ 
$200 \mu \mathrm{mol} / \mathrm{L} \mathrm{MSC}$ for $24 \mathrm{~h}$ resulted the highest viability $(82.67 \pm 2.28 \%)$ of HAECs. However, with the concentration of MSC increased to $400 \mu \mathrm{mol} / \mathrm{L}$, the cell viabil-
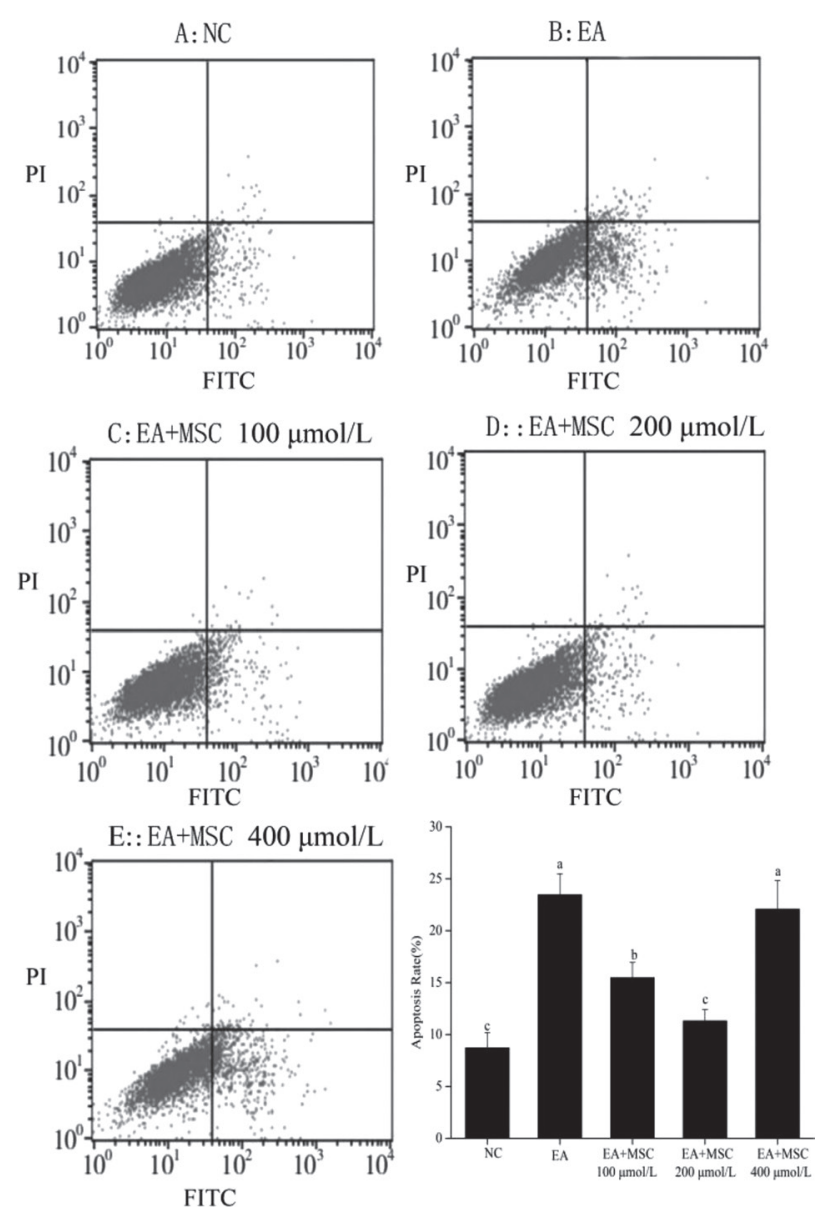

Fig. 2. Effect of EA and MSC on HAECs apoptosis. Cell apoptosis was measure by flow cytometry analysis (FACS) after treated with EA or EA+MSC for $24 \mathrm{~h}$. Data are expressed as mean \pm SD. Different characters on the bar mean significant differences $(p<0.05)$. ity decreased significantly at $24 \mathrm{~h}(62.85 \pm 1.84 \%)$ or $48 \mathrm{~h}(51.66 \pm 2.27 \%)$ when compared with the EA group $(68.34 \pm 2.51 \%$ and $57.55 \pm 3.17 \%$ at $24 \mathrm{~h}$ and 48 h respectively) $(p<0.05)$.

\section{Cell apoptosis}

After incubated with EA for $24 \mathrm{~h}$, the aopoptosis rate of HAECs was significantly increased when compared with NC group $(23.47 \pm 1.47 \%$ vs. $8.72 \pm 1.47 \%, p<$ 0.05). After stimulated with EA+MSC $(100 \mu \mathrm{mol} / \mathrm{L}$ and $200 \mu \mathrm{mol} / \mathrm{L}$ ), the aopotosis rate was decreased dramatically in a dose-dependent manner (15.47 $\pm 3.48 \%$ and $11.32 \pm 1.09 \%$ respectively) compared with EA group $(p<0.05)$. However, there was no significant change of the aopotosis rate between EA+MSC 400 $\mu \mathrm{mol} / \mathrm{L}$ group and EA group ( $p>0.05$ ) (Fig. 2).

Expression of inflammatory cytokines

The expression level of inflammatory related factors, ICAM-1, E-selectin, and IL-8 were significantly increased $(p<0.05)$, and the expression level of e-NOS was decreased in the EA group when compared with the NC group $(p<0.05)$. Meanwhile, MSC significantly reversed the adverse effect of $\mathrm{EA}$ in $\mathrm{EA}+\mathrm{MSC}$ group. And pretreatment cells with PLA2 inhibitors for $1 \mathrm{~h}$, and then incubated with EA+MSC, the expression level of ICAM-1, E-selectin (except EA+MSC+PYR group) and IL-8 significantly increased when compared with EA + MSC group $(p<0.05)$. Also, the expression level of e-NOS decreased significantly in the EA+MSC+BEL group compared with EA+MSC group ( $p<0.05)$ (Fig. 3). Expression of PLA2

As shown in Fig. 4, the expression of all four kinds of PLA2 (iPLA2, sPLA2, cPLA2 and cPLA2 phosphorylation (p-cPLA2)) were dramatically increased in HAECs after incubated with EA for $24 \mathrm{~h}$ compared with $\mathrm{NC}$ group $(p<0.05)$, and obvious up-regulation of sPLA2 was found in EA group. Moreover, the expression of PLA2 significantly decreased after treatment of EA+ MSC $(100 \mu \mathrm{mol} / \mathrm{L}$ and $200 \mu \mathrm{mol} / \mathrm{L})$, especially for the expression level of p-cPLA2 at the group treated with
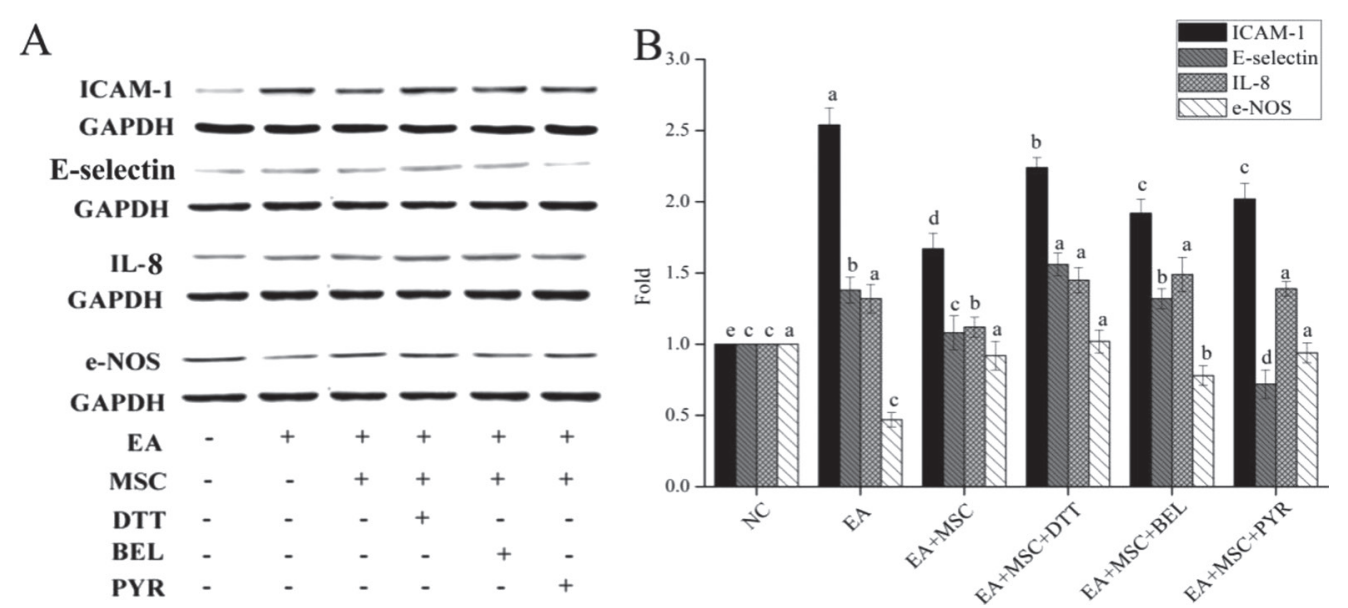

Fig. 3. Effect of EA and MSC on protein expression of ICAM-1, E-selectin, IL-8 and e-NOS. Cells were pre-treated with PLA2 inhibitors for $1 \mathrm{~h}$ and then stimulated with EA or EA+MSC for $24 \mathrm{~h}$. The total cellular proteins were extracted and separated by SDS-PAGE. Specific antibodies raise against ICAM-1, E-selectin, IL-8 and e-NOS were used in the Western blot assay with the GAPDH for normalization (A). Data are expressed as mean \pm SD (B). Different characters in each set (ICAM-1, E-selectin, IL-8 and e-NOS) indicate significant differences $(p<0.05)$. 
A
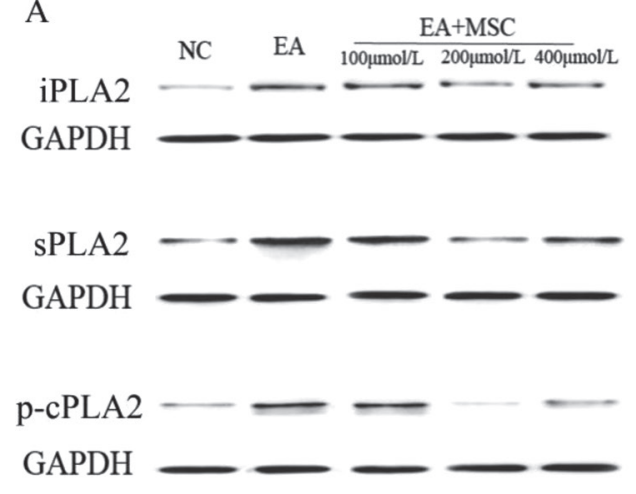

cPLA2

GAPDH
B

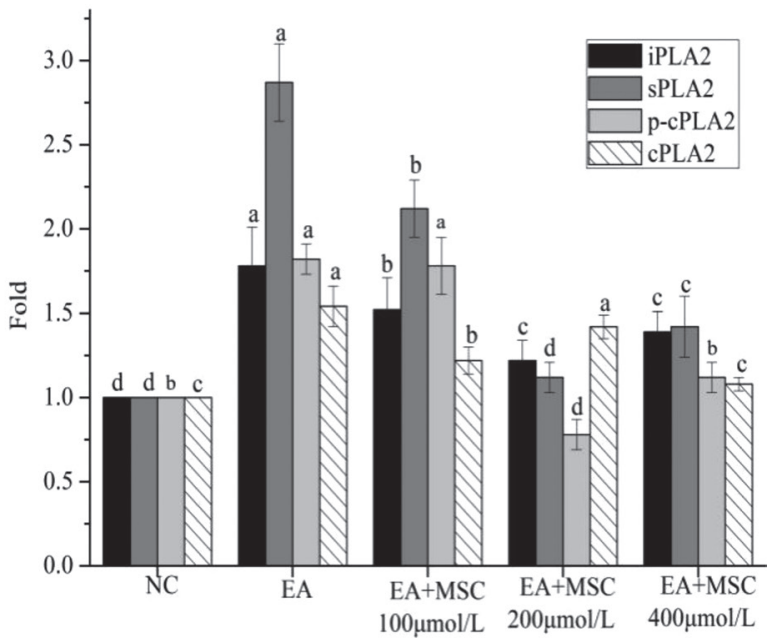

Fig. 4. Effect of EA and MSC on protein expression of PLA2. Cells were treated with EA or EA+MSC for 24 h (A). Data are expressed as mean \pm SD (B). Different characters in each set (iPLA2, sPLA2, cPLA2 and p-cPLA2) mean significant differences $(p<0.05)$.

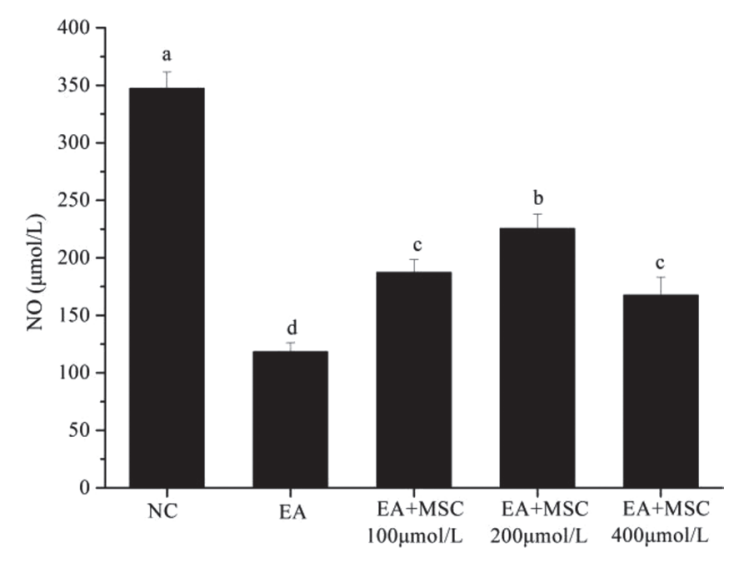

Fig. 5. Effect of EA and MSC on secretions of NO in HAECs. Cells were treated with EA or EA+MSC for 24 h. Data are expressed as mean \pm SD. Different characters on the bars mean significant differences $(p<0.05)$.

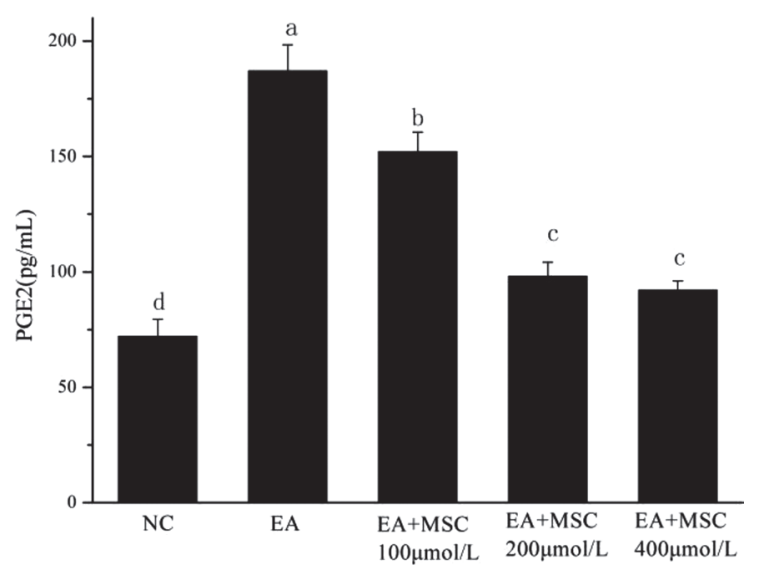

Fig. 6. Effect of EA and MSC on secretions of PGE2 in HAECs. Cells were treated with EA or EA+MSC for $24 \mathrm{~h}$. Data are expressed as mean \pm SD. Different characters on the bars mean significant differences $(p<0.05)$.
EA+MSC $200 \mu \mathrm{mol} / \mathrm{L}$ compared with EA group ( $p<$ 0.05).

Secretion of NO and PGE2

Figure 5 represent the effect of EA and MSC on the secretion level of $\mathrm{NO}$ in HAECs. EA significantly decreased the secretion of NO compared with NC group $(p<0.05)$. MSC (100, 200 and $400 \mu \mathrm{mol} / \mathrm{L})$ significantly reversed the effect of EA. The EA+MSC $(200 \mu \mathrm{mol} / \mathrm{L})$ group shows strongest effect among all EA+MSC groups $(p<0.05)$. Figure 6 shows PGE2 levels in HAECs. Compared with NC group, EA significantly increased the secretion of PGE2 $(p<0.05)$. After treatment with MSC, PGE2 section decreased significantly compared with EA group $(p<0.05)$.

\section{DISCUSSION}

In the present study, we found that EA significantly decrease the viability of HAECs and increase apoptosis, and MSC dose-dependently reverse this adverse effect. The most appropriate concentration and duration of MSC to incubate with HAECs might be $200 \mu \mathrm{mol} / \mathrm{L}$ and $24 \mathrm{~h}$. The apoptosis rate of HAECs increased obviously when co-incubated with $\mathrm{EA}+400 \mu \mathrm{mol} / \mathrm{L} \mathrm{MSC}$ may due to cytotoxicity of MSC at high concentration (17). Reported studies approved that the most two common existence forms of selenium, inorganic selenium (such as sodium selenite) and organic selenium (such as methylseleninic acid and Se-methylselenocysteine) may exert bioactive or cytotoxic effects in vitro strictly depend on compound, concentration and model used $(14,18)$. We use MSC in our model because increasing studies supported that MSC has stronger bioactivity than other forms of selenium in vitro (19).

Atherosclerosis is one of the leading causes of death over the world, and the dysfunction of endothelial cells was considered as the initial factor of atherosclerosis. Selenium has been proved as a crucial non-metal trace element in the process of metabolism of life. Although 
limited numbers of prospective research reported inconsistent result on the protect effect of selenium on atherosclerosis, the benefit of selenium and selenoproteins supplementation has been verified to protect experimental vascular injury (20). In the present study, we stimulated HAECs with EA, one of the major TFA forms in human diet, and then investigate the protect effect of MSC on HAECs inflammation. Our results revealed that MSC could reverse the pro-inflammatory effect of EA. In addition, the secretion level of PGE2 (a down-stream product of AA) in EA group was significantly higher than EA+SMC groups (Fig. 6). This effect of MSC may due to its anti-inflammation power through AA. The oxidation products of AA, including hydroperoxyeicosatetraenoic acids (HpETEs) could promote inflammation, and reports found that HpETEs can be reduced by glutathione peroxidase $4(\mathrm{GPx} 4)(21)$, one of the family members of GPxs, which containing about $4 \mathrm{~g}$ of selenium atoms per 1 mole (17). Furthermore, GPx4 also benefit for anti-inflammation by inhibiting the nuclear factor kappa-B $(\mathrm{NF}-\kappa \mathrm{B})$ pathway, reducing the expression of lipoxygenase and cyclooxygenase (22-25). Despite the abundant anti-inflammatory mechanisms of MSC, but whether and how MSC inhibit the generation of AA still unclear.

PLA2 is widely distributed in the biological cell membrane. The main function of PLA2 is hydrolyzes phospholipids and then generate free fatty acids, including AA and lysolecithin, which induce endothelial dysfunction (7). Previous study reported that cPLA2 could be activated by stimulating of $\mathrm{H}_{2} \mathrm{O}_{2}$ via ERK pathway (26), and it could also be activated by IL- 6 , TNF- $\alpha$ and histamine $(27,28)$. Also, many studies found stronger activity of cPLA2 in inflammatory cells than non-inflammatory cells (29). Ma et al. (30) reported that up-regulation of sPLA2 involved in inflammatory pathological injury to hepatopancreas caused by phoxim. Sato et al. (31) revealed that enhanced decomposition of cardiolipin following mitochondrial iPLA2 activation might mediate trogitazone-induced mitochondrial membrane permeability transition.

In the present study, we found that EA induced the expression of PLA2, and EA+MSC groups were negatively correlated with the PLA2 expression level. The expression of ICAM-1, E-selectin, and IL- 8 were also significantly decreased in EA+MSC groups compared with EA group $(p<0.05)$. However, groups pretreated with PLA2 inhibitor (DTT, BEL and PYR) were positively correlated with the expression of those inflammatory cytokines (ICAM-1, IL-8) compared with the EA+MSC group $(p<0.05)$. Meanwhile, the E-selectin level in groups pretreated with inhibitor (DTT and BEL) were higher than EA+MSC group $(p<0.05)$, and e-NOS level in group pretreated with inhibitor (DTT and PYR) showed no significant difference with EA+MSC group ( $p>0.05)$, and inhibitor BEL depress expression of e-NOS compared with EA+MSC group $(p<0.05)$. Based on these results, we assume that PLA2 may involved in the ICAM-1, IL-8 and E-selectin expression in EA induced HAECs inflammation. This results were coordinate with
Hu's report (32), and we first revealed that PLA2 may not participate in EA induced e-NOS expression in HAECs.

Nitric oxide, known as the main chemical substance for maintaining normal vascular homeostasis, was produced by e-NOS. Previous studies have shown that selenium supplementation for $3 \mathrm{~d}$ enhanced NO release in acetycholine-induced rats (33). Lu et al. also reported that selenium supplementation increased NO secretion in homocysteine-induced endothelial injury (34). In our study, we also find that NO and e-NOS were significantly decreased after treated with EA, and MSC significantly induced NO release and e-NOS expression compared with EA group. Interestingly, our results demonstrated that only PLA2 inhibitors of BEL suppressed expression of e-NOS compared with inhibitor free group. These results suggested that PLA2 pathway may not involve in secretion of NO in our model, and further potential underlying mechanisms need to be clarified.

Nonetheless, there are some limitations in this in vitro study. The antioxidant system in which selenium involved is very complex, other solutes except PLA2 may interact the biological system. So, more in vivo and clinical trials should be carried out to better verify the protective effect of SMC on EA induced HAECs.

\section{Authorship}

Jizhu Xia designed this study, Xiaorong Xia and Wenyuan Wang collected and analyzed the data, Jiyi Xia and Mingxing Li wrote and approved the final version of the manuscript. All authors read and approved the manuscript for publication.

\section{Disclosure of state of COI}

The authors declare that they have no conflict of interests.

\section{Acknowledgments}

We thank the National Nature Science Foundation of China (No. 81501481); Key technologies R\&D program of Sichuan (2015SZ0116); Joint Project of Science and Technology Department of Sichuan Province and Luzhou City (14JC0130).

\section{REFERENCES}

1) Mozaffarian D, Clarke R. 2009. Quantitative effects on cardiovascular risk factors and coronary heart disease risk of replacing partially hydrogenated vegetable oils with other fats and oils. Eur J Clin Nutr 63: S22-S33.

2) Wang Y, Jacome-Sosa MM, Proctor SD. 2012. The role of ruminant trans fat as a potential nutraceutical in the prevention of cardiovascular disease. Food Res Int 46: 460-468.

3) Willett WC, Stampfer MJ, Manson JE, Colditz GA, Speizer FE, Rosner BA, Sampson LA, Hennekens CH. 1993. Intake of trans-fatty-acids and risk of coronary heartdisease among women. Lancet 341: 581-585.

4) Harvey KA, Walker CL, Pavlina TM, Xu ZD, Zaloga GP, Siddiqui RA. 2008. Trans-fatty acids induce pro-infammatory responses and endothelial cell dysfunction. $\mathrm{Br}$ J Nutr 99: 723-731. 
5) Iwata NG, Pham M, Rizzo NO, Cheng AM, Maloney E, Kim F. 2011. Trans fatty acids induce vascular inflammation and reduce vascular nitric oxide production in endothelial cells. PloS One 6: 1-6.

6) Kummerow FA, Zhou Q, Mahfouz MM, Smiricky MR, Grieshop CM, Schaeffer DJ. 2004. Trans fatty acids in hydrogenated fat inhibited the synthesis of the polyunsaturated fatty acids in the phospholipid of arterial cells. Life Sci 74: 2707-2723.

7) Liu SY, Lu X, Choy S, Dembinski ST, Hatch GM, Mymin D, Shen X, Angel A, Choy PC, Man RYK. 1994. Alteration of lysophosphatidylcholine content in low density lipoprotein after oxidative modification: relationship to endothelium dependent relaxation. Cardiovasc Res $\mathbf{2 8}$ : 1476-1481.

8) Benstoem C, Goetzenich A, Kraemer S, Borosch S, Manzanares W, Hardy G, Stoppe C. 2015. Selenium and its supplementation in cardiovascular disease-what do we know? Nutrients 7: 3094-3118.

9) Zhang X, Liu C, Guo J, Song Y. 2016. Selenium status and cardiovascular diseases: Meta-analysis of prospective observational studies and randomized controlled trials. Eur J Clin Nutr 70: 162-169.

10) Zhang F, Yu W, Hargrove JL, Greenspan P, Dean RG, Taylor EW, Hartle DK. 2002. Inhibition of TNF-alpha induced ICAM-1, VCAM-1 and E-selectin expression by selenium. Atherosclerosis 161: 381-386.

11) Zheng HT, Zhou LN, Huang CJ, Hua X, Jian R, Su BH, Fang F. 2008. Selenium inhibits high glucose- and high insulin-induced adhesion molecule expression in vascular endothelial cells. Arch Med Res 39: 373-379.

12) Sordillo LM, Streicher KL, Mullarky IK, Gandy JC, Trigona W, Corl CM. 2008. Selenium inhibits 15-hydroperoxyoctadecadienoic acid-induced intracellular adhesion molecule expression in aortic endothelial cells. Free Radical Biol Med 44: 34-43.

13) Ren H, Mu J, Ma J, Gong J, Li J, Wang J, Gao T, Zhu P, Zheng S, Xie J, Yuan B. 2016. Selenium inhibits homocysteine-induced endothelial dysfunction and apoptosis via activation of AKT. Cell Physiol Biochem 38: 871882.

14) Liu Y, Li W, Guo MY, Li CY, Qiu CW. 2015. Protective role of selenium compounds on the proliferation, apoptosis, and angiogenesis of a canine breast cancer cell line. Biol Trace Elem Res 169: 86-93.

15) Li XP, Luo T, Li J, Fan YW, Liu R, Hu JN, Liu XR, Deng ZY. 2013. Linolelaidic acid induces a stronger proliferative effect on human umbilical vein smooth muscle cells compared to elaidic acid. Lipids 48: 395-403.

16) Wan R, Liu Y, Li L, Zhu C, Jin L, Li S. 2014. Urocortin increased endothelial ICAM1 by cPLA2-dependent NF- $\kappa$ B and PKA pathways in HUVECs. J Mol Endocrinol 52: 43-53.

17) Fairweather-Tait S.J, Bao YP. Broadley MR, Collings R, Ford D, Hesketh JE, Hurst R. 2011. Selenium in human health and disease. Antioxid Redox Signal 14: $1337-$ 1382.

18) Jariwalla RJ, Gangapurkar B, Nakamura D. 2009. Differential sensitivity of various human tumour-derived cell types to apoptosis by organic derivatives of selenium. Br J Nutr 101: 182-189.
19) Yao Z, Zhang YL, Li HY, Deng ZY, Zhang XP. 2015. Synergistic effect of Se-methylselenocysteine and vitamin E in ameliorating the acute ethanol-induced oxidative damage in rat. J Trace Elem Med Bio 29: 182-187.

20) Tanguy S, Grauzam S, de Leiris J, Boucher F. 2012. Impact of dietary selenium intake on cardiac health: experimental approaches and human studies. Mol Nutr Food Res 56: 1106-1121.

21) Imai H, Narashima K, Arai M, Sakamoto H, Chiba N, Nakagawa Y. 1998. Suppression of leukotriene formation in RBL-2H3 cells that overexpressed phospholipid hydroperoxide glutathione peroxidase. J Biol Chem 273: 1990-1997.

22) Flohe L, Günzler WA, Schock HH. 1973. Glutathione peroxidase: A selenoenzyme. FEBS Lett 32: 132-134.

23) Brigelius-Flohé R. 2006. Glutathione peroxidases and redox-regulated transcription factors. Biol Chem $\mathbf{3 8 7}$ : 1329-1335.

24) Yang K, Ma W, Liang H, Ouyang Q, Tang C, Lai L. 2007. Dynamic simulations on the arachidonic acid metabolic network. PLoS Comput Biol 3: e55.

25) Yang K, Bai H, Ouyang Q, Lai L, Tang C. 2008. Finding multiple target optimal intervention in disease-related molecular network. Mol Syst Biol 4: 228.

26) Pei J, Yin N, Ma X, Lai L. 2014. Systems biology brings new dimensions for structure-based drug design. J Am Chem Soc 136: 11556-11565.

27) Yang J, Yang S, Gao X, Yuan YJ. 2011. Integrative investigation of lipidome and signal pathways in human endothelial cells under oxidative stress. Mol BioSyst 7: 2428-2440.

28) Akiba S, Hatazawa R, Ono K, Kitatani K, Hayama M, Sato T. 2001. Secretory phospholipase A2 mediates cooperative prostaglandin generation by growth factor and cytokine independently of preceding cytosolic phospholipase A2 expression in rat gastric epithelial cells. J Biol Chem 276: 21854-21862.

29) Gudmundsdottir IJ, Halldorsson H, Magnusdottir K, Thorgeirsson G. 2001. Involvement of MAP kinases in the control of cPLA(2) and arachidonic acid release in endothelial cells. Atherosclerosis 156: 81-90.

30) Ma RR, Zhou GX, Feng DY, Fang WH, Chen TN, Hu K. 2020. Transcriptome analysis of Penaeus vannamei hepatopancreas reveals differences in toxicity mechanisms between phoxim and prometryne. Fish Shellfish Immunol 105: 274-285.

31) Sato T, Segawa M, Sekine S, Ito K. 2019. Mild depolarization is involved in troglitazone-induced liver mitochondrial membrane permeability transition via mitochondrial iPLA2 activation. J Toxicol Sci 44: 811-820.

32) Hu SB, Zou Q, Lv X, Zhou RL, Niu X,Weng C, Chen F, Fan YW, Deng ZY, Li J. 2020. 9t18: 1 and 11t18: 1 activate the MAPK pathway to regulate the expression of PLA2 and cause inflammation in HUVECs. Food Funct 11: 649-661.

33) Capper EA, Marshall LA. 2001. Mammalian phospholipases $A(2)$ : mediators of inflammation, proliferation and apoptosis. Prog Lipid Res 40: 167-197.

34) Lu X, Liu SY, Man RY. 1994. Enhancement of endothelium dependent relaxation in the rat aortic ring by selenium supplement. Cardiovasc Res 28: 345-348. 